\title{
Heat Capacity Changes for Transition-State Analogue Binding and Catalysis with Human 5'-Methylthioadenosine Phosphorylase
}

\author{
Ross S. Firestone, ${ }^{\dagger}$ Scott A. Cameron, ${ }^{\dagger}$ Jerome M. Karp, ${ }^{\dagger}$ Vickery L. Arcus, ${ }^{\dagger}$ and Vern L. Schramm*, ${ }^{\dagger}$ \\ ${ }^{\dagger}$ Department of Biochemistry, Albert Einstein College of Medicine, 1300 Morris Park Avenue, Bronx, New York 10461, United States \\ ${ }^{\ddagger}$ Faculty of Science and Engineering, Department of Biological Science, University of Waikato, Private Bag 3105, Hamilton, New \\ Zealand
}

Supporting Information

ABSTRACT: Human 5'-methylthioadenosine phosphorylase (MTAP) catalyzes the phosphorolysis of 5'-methylthioadenosine (MTA). Its action regulates cellular MTA and links polyamine synthesis to $S$-adenosylmethionine (AdoMet) salvage. Transition state analogues with picomolar dissociation constants bind to MTAP in an entropically driven process at physiological temperatures, suggesting increased hydrophobic character or dynamic structure for the complexes. Inhibitor binding exhibits a negative heat capacity change $\left(-\Delta C_{p}\right)$, and thus the changes in enthalpy and entropy upon binding are strongly temperature-dependent. The $\Delta C_{\mathrm{p}}$ of inhibitor binding by isothermal titration calorimetry does not follow conventional

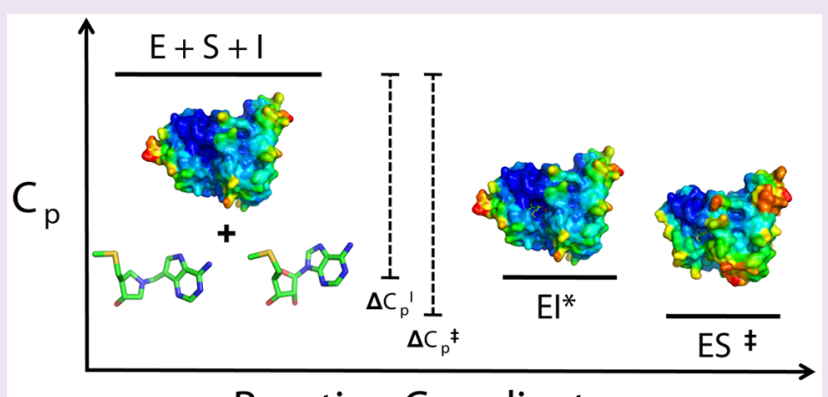

Reaction Coordinate trends and is contrary to that expected from the hydrophobic effect. Thus, ligands of increasing hydrophobicity bind with increasing values of $\Delta C_{\mathrm{p}}$. Crystal structures of MTAP complexed to transition-state analogues MT-DADMe-ImmA, BT-DADMeImmA, PrT-ImmA, and a substrate analogue, MT-tubercidin, reveal similar active site contacts and overall protein structural parameters, despite large differences in $\Delta C_{p}$ for binding. In addition, $\Delta C_{p}$ values are not correlated with $K_{d}$ values. Temperature dependence of presteady state kinetics revealed the chemical step for the MTAP reaction to have a negative heat capacity for transition state formation $\left(-\Delta C_{\mathrm{p}}^{\ddagger}\right)$. A comparison of the $\Delta C_{\mathrm{p}}^{\ddagger}$ for MTAP presteady state chemistry and $\Delta C_{\mathrm{p}}$ for inhibitor binding revealed those transition-state analogues most structurally and thermodynamically similar to the transition state. Molecular dynamics simulations of MTAP apoenzyme and complexes with MT-DADMe-ImmA and MT-tubercidin show small, but increased dynamic motion in the inhibited complexes. Variable temperature CD spectroscopy studies for MTAP-inhibitor complexes indicate remarkable protein thermal stability (to $T_{\mathrm{m}}=99^{\circ} \mathrm{C}$ ) in complexes with transition-state analogues.

T uman 5'-methylthioadenosine phosphorylase (MTAP) 1 provides the only metabolic path to recycle $5^{\prime}$ methylthioadenosine (MTA) formed in the polyamine synthesis pathway. ${ }^{1}$ Each donation of an $n$-propylamino group from decarboxy-S-adenosyl-L-methionine forms an equivalent of MTA as an end-product metabolite. In humans, only the polyamine pathway produces MTA, and MTAP is the only means of MTA metabolism. The MTA undergoes phosphorolysis by MTAP, forming adenine and 5-methylthio- $\alpha$-D-ribose-1-phosphate. These enter the ATP and methionine salvage pathways for resynthesis of S-adenosyl-L-methionine (AdoMet) (Figure 1). ${ }^{2}$ MTAP is also the only enzyme producing adenine in humans. The significance of the MTAP-AdoMet pathway has been established in humans genetically deficient in adenine phosphoribosyl transferase (APRT, Figure 1), where approximately $20 \%$ of the normal uric acid content of the urine is replaced by 2,8-dihydroxyadenine, a result of adenine oxidation by xanthine oxidase. ${ }^{3}$ Thus, a significant fraction of the total purine economy passes through MTAP.

Polyamine synthesis and AdoMet salvage are crucial for rapid cellular growth. ${ }^{4,5}$ Surprisingly, a genetic deletion of MTAP occurs in approximately $15 \%$ of human cancers. This deletion causes increased cellular MTA concentration, a known inhibitor of polyamine synthesis and PRMT5 histone methyltransferase. Thus, MTAP-deleted cancers are more susceptible to anticancer targeting by inhibitors of PRMT5. ${ }^{6-9}$ Logically, the use of MTAP inhibitors on human cancers expressing MTAP would render them equally susceptible to PRMT5 therapy as MTAP-deleted tumors.

The transition state structure of human MTAP has been reported from kinetic isotope effect experiments. ${ }^{10}$ The transition state (TS) of human MTAP indicates a late dissociative $S_{\mathrm{N}} 1$ mechanism (Figure $2 \mathrm{~A}$ ), and several chemical classes of MTAP transition-state analogues have been developed with dissociation constants in the nanomolar to picomolar range (Figure 2B). ${ }^{11,12}$ One such inhibitor, MT-DADMe-ImmA, has shown antineoplastic activity in cellular and animal cancer models. ${ }^{13-15}$ However, the compound that exhibits the tightest

Received: October 5, 2016

Accepted: December 6, 2016

Published: December 6, 2016 


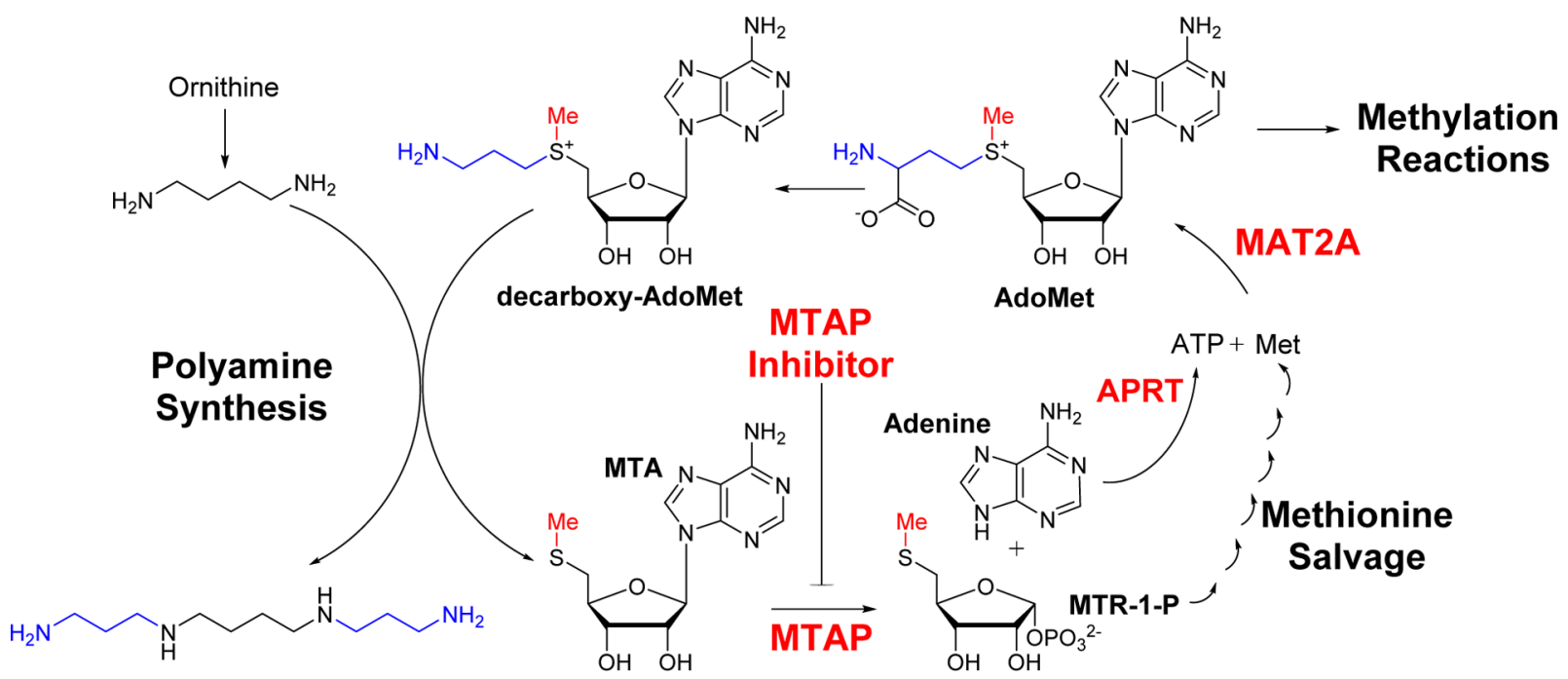

Figure 1. MTA metabolism in the context of AdoMet. Spermine biosynthesis from ornithine requires two equivalents of decarboxy-AdoMet and forms two MTA equivalents as products. MTA is phosphorylated by MTAP to form adenine and MTR-1-P, a precursor for methionine salvage. Adenine is salvaged by APRT and kinases to reform ATP..$^{13}$<smiles>CSCC1OC2OC(C(O)C2O)C1n1cnc2c(N)ncnc21</smiles>

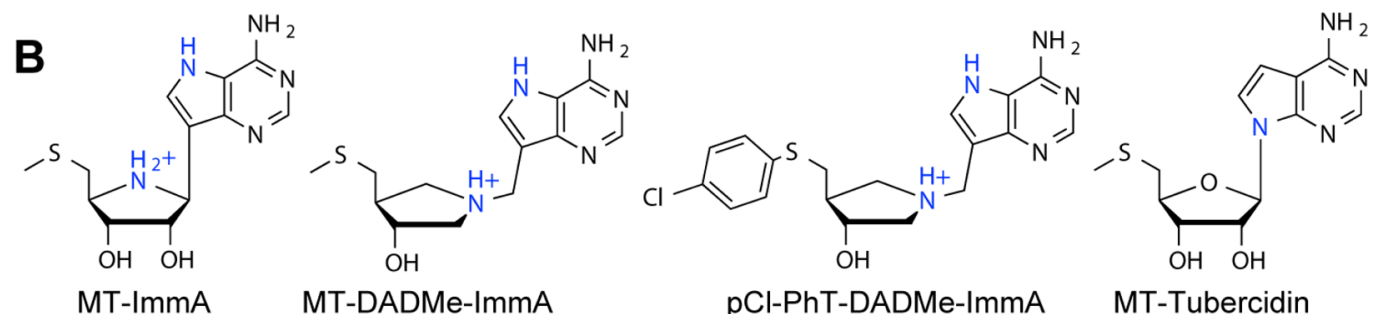

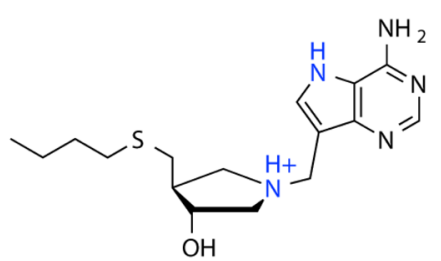

BT-DADMe-ImmA<smiles>O=c1[nH]cnc2c(CN3CCCCC3O)c[nH]c12</smiles>

DADMe-ImmH

Figure 2. MTAP transition state and TS analogues. (A) Transition state structure reported for human MTAP showing a late dissociative, $S_{N} 1$ transition state. (B) Structures of an iminoribitol MTAP TS analogue (MT-ImmA), three hydroxypyrrolidine analogues (MT-DADMe-ImmA, $p$ Cl-PhTDADMe-ImmA, BT-DADMe-ImmA), an MTAP substrate analogue (MT-tubercidin), and a purine nucleoside phosphorylase hydroxypyrrolidine TS analogue (DADMe-ImmH). Analogues in B have five (DADMe-ImmH), seven (MT-ImmA, MT-DADMe-ImmA, pCl-PhT-DADMe-ImmA, MTTubercidin), or 10 (BT-DADMe-ImmA) rotatable bonds.

binding may not necessarily be the compound with the highest similarity to the MTAP transition state. The tightest binding compound, $p$ Cl-PhT-DADMe-ImmA $\left(K_{\mathrm{i}}^{*}=10 \mathrm{pM}\right)$ is less similar to the MTAP transition state than MT-DADMe-ImmA $\left(K_{\mathrm{i}}^{*}=86 \mathrm{pM}\right)$ or MT-ImmA $\left(K_{\mathrm{i}}^{*}=1 \mathrm{nM}\right)$ despite having higher affinity for the enzyme (Figure 2 ). The tighter binding of $p \mathrm{Cl}$ PhT-DADMe-ImmA has been proposed to be due to a hydrophobic interaction on MTAP near the $5^{\prime}$-methylthiol group, in addition to incorporation of transition state features. ${ }^{16}$ Here, we explore heat capacity, kinetic, structural, and molecular dynamic parameters to compare interactions of transition-state analogues with catalytic properties of MTAP.

Preliminary thermodynamic profiles of transition-state analogues binding to MTAP have been reported ${ }^{17,18}$ and are unique 

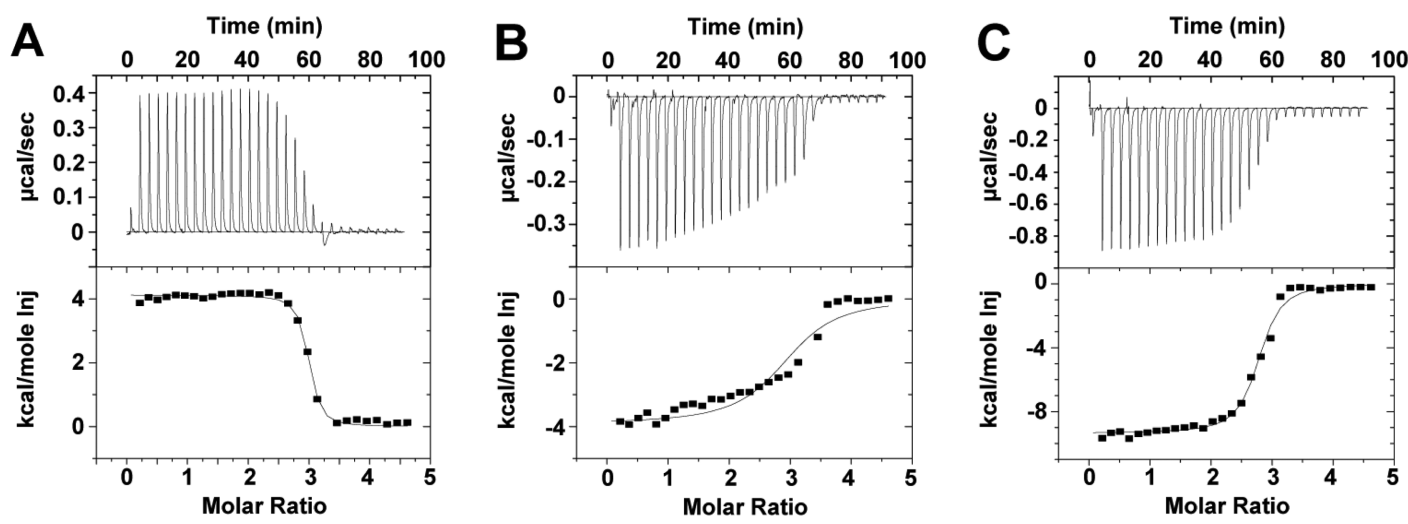

Figure 3. Isothermal titration of human MTAP with MT-DADMe-ImmA. Experiments were conducted at (A) $20^{\circ} \mathrm{C}$, (B) $37^{\circ} \mathrm{C}$, and (C) $46^{\circ} \mathrm{C}$. All three titrations were fit to a single site filling model. This titration exemplifies the interactions of MTAP with transition-state analogues. Note the enthalpic changes ( 4 to $-9 \mathrm{kcal} / \mathrm{mol}$ ) relative to the $\Delta G$ of $-14 \mathrm{kcal} / \mathrm{mol}$ for MT-DADMe-ImmA binding at its optimal temperature (Figure 4). Numerical values for all titrations are listed in Table 1.

among known $N$-ribosyltransferases by being dominated by entropic factors at physiological temperatures. In contrast, binding of transition-state analogues to human purine nucleoside phosphorylase (PNP) and 5'-methylthioadenosine nucleosidase (MTAN) are driven primarily or entirely by enthalpy. ${ }^{19,20}$ Enthalpic binding is readily explained in these cases by the formation of new hydrogen and ionic bonds in complexes of the transition-state analogues, when compared to the Michaelis complexes. Entropy-driven binding may occur as a consequence of populating low frequency protein vibrational modes, ${ }^{21}$ exclusion of active site water molecules following binding, or protein reorganization to increase hydrophobic interactions, for example between subunits in this homotrimeric enzyme. ${ }^{22}$ The entropy-driven binding of MT-ImmA to MTAP is highly temperature-sensitive, resulting in the negative value for $\Delta C_{\mathrm{p}} .{ }^{17}$ Thus, as temperature increases, the entropic component goes to zero, and inhibitor binding to MTAP becomes increasingly enthalpically driven to more closely resemble transition state inhibitor interactions with other $N$-ribosyltransferases. Negative values of $\Delta C_{p}$ also confer a marked curvature to the temperaturedependence of $\Delta G$ such that there is a minimum value for $\Delta G$ (i.e., optimum binding) at a specific temperature. At this optimum temperature, $\Delta S$ for binding is zero.

The heat capacity of an enzyme refers to the amount of energy required to increase its temperature (formally, $C_{\mathrm{p}}=(\mathrm{d} H / \mathrm{d} T)_{\mathrm{p}}=$ $\left.T(\mathrm{~d} S / \mathrm{d} T)_{\mathrm{p}}\right)$, while the change in heat capacity for a process is simply the temperature dependence of the change in enthalpy for that process $\Delta C_{\mathrm{p}}=(\mathrm{d} \Delta H / \mathrm{d} T)_{\mathrm{p}}$. However, in the case of most enzyme-catalyzed reactions, the heat capacity decreases for the formation of the transition state, which corresponds to a negative value for $\Delta C_{\mathrm{p}}^{\ddagger}$. ${ }^{23,24}$ A nonzero $\Delta C_{\mathrm{p}}$ upon transition-state formation indicates that the reaction has an additional layer of temperature sensitivity and, if quantified, can be used to determine the optimal temperature $\left(T_{\text {opt }}\right)$, including formation of the transition state. Studying MTAP heat capacity and how it changes with analogue binding and catalysis gives insight into the temperature-structure relationship of this important enzyme.

The negative heat capacity change reported for MT-ImmA binding has been postulated to result from a decrease in solventaccessible surface area for the system. ${ }^{18}$ The exclusion of active site water molecules following ligand binding was also considered as a possible contributor to this effect. ${ }^{17}$ Here, we explore the unusual thermodynamics of transition-state analogue binding to MTAP by comparing the heat capacity changes for binding a series of inhibitors with the heat capacity of enzyme chemistry and the dynamic and structural properties of several MTAPinhibitor complexes.

\section{RESULTS AND DISCUSSION}

Isothermal Titration Calorimetry. MTAP Isothermal Titration Calorimetry (ITC) experiments with transition-state analogues MT-ImmA, MT-DADMe-ImmA, pCl-PhT-DADMeImmA, BT-DADMe-ImmA, and the substrate analogue MTtubercidin were conducted as a function of temperature. By way of a comparative internal standard, similar experiments were conducted with human purine nucleoside phosphorylase and DADMe-ImmH, a picomolar TS analogue known to interact with an enthalpy-driven binding equilibrium. ${ }^{25}$

ITC data were fit to the appropriate equations to determine the enthalpy values as a function of temperature. Plots of enthalpy as a function of temperature were used to establish heat capacity change for analogue binding (see below).

Dissociation constants were determined from reference steady-state kinetic data as tight-binding inhibitors give nearstoichiometric ITC interactions over most of the experimental titration range. ${ }^{11,12}$ An exception was the ITC titration of MTtubercidin, where weaker binding permitted calculation of the dissociation constant directly from ITC data

MTAP is a functional homotrimer by crystallographic analysis. ${ }^{26}$ However, all titrations were consistent with a single site filling titration model (independent monomers), with two exceptions. Titration of BT-DADMe-ImmA showed a unique thermodynamic profile for filling the third active site exclusively at $37{ }^{\circ} \mathrm{C}$. In the control titration of human PNP (also a homotrimer) with DADMe-ImmH, catalytic site filling followed a two-site model, consistent with previous reports (Figure 3). ${ }^{20}$ In these cases, the enthalpic component for filling of the first catalytic sites was used. Functionally, filling of the first site of human PNP causes complete catalytic inhibition of the enzyme trimer.

Enthalpy and Heat Capacity Changes for MTAP Inhibitor Binding. ITC studies at 20, 37, and $46{ }^{\circ} \mathrm{C}$ (e.g., Figure 3) gave enthalpy values that yielded linear regressions when plotted against temperature values (Figure S1). The slopes correspond to the heat capacity change $\left(\Delta C_{p}\right)$ upon binding. ${ }^{27}$ Linear regressions had coefficients of determination from 0.996 to 0.9999 , giving correspondingly small experimental errors in heat capacity analysis (Table 1, Figure S1). 
Table 1. ITC, $\Delta C_{\mathrm{p}}$, and $K_{\mathrm{i}}$ values for MTAP and Comparison to PNP (DADMe-ImmH) ${ }^{a}$

\begin{tabular}{|c|c|c|c|c|c|c|}
\hline compound & $\underset{\mathrm{mol})}{\Delta H 20{ }^{\circ} \mathrm{C}(\mathrm{kcal} /}$ & $\underset{\mathrm{mol})}{\Delta H 37^{\circ} \mathrm{C}(\mathrm{kcal} /}$ & $\underset{\mathrm{mol})}{\Delta H 46^{\circ} \mathrm{C}(\mathrm{kcal} /}$ & $\Delta C_{\mathrm{p}}(\mathrm{kcal} / \mathrm{mol} /$ & $\begin{array}{l}\text { dissociation constant } \\
\left(K_{\mathrm{i}}^{*}\right)^{c}\end{array}$ & $\begin{array}{c}\text { polar surface area } \\
\qquad\left(\AA^{2}\right)^{f}\end{array}$ \\
\hline MT-ImmA & $3.0 \pm 0.1$ & $-6.6 \pm 0.1$ & $-12.0 \pm 0.2$ & $-0.58 \pm 0.01$ & $1 \pm 0.5 \mathrm{nM}^{12}$ & 120 \\
\hline MT-DADMe-ImmA & $4.1 \pm 0.03$ & $-3.9 \pm 0.1$ & $-9.4 \pm 0.1$ & $-0.51 \pm 0.03$ & $86 \pm 10 \mathrm{pM}^{11}$ & 91 \\
\hline pCl-PhT-DADMe- & $3.8 \pm 0.04$ & $-3.1 \pm 0.02$ & $-7.5 \pm 0.03$ & $-0.43 \pm 0.02$ & $10 \pm 5 \mathrm{pM}^{11}$ & 91 \\
\hline $\operatorname{ImmA}^{d}$ & $3.2 \pm 0.1$ & $5.9 \pm 0.1$ & $5.7 \pm 0.1$ & & & \\
\hline MT-Tubercidin & $4.8 \pm 0.1$ & $-1.6 \pm 0.1$ & $-5.9 \pm 0.1$ & $-0.38 \pm 0.002$ & $1.8 \pm 0.2 \mu \mathrm{M}^{e}$ & 106 \\
\hline BT-DADMe-ImmA & $5.5 \pm 0.1$ & $-1.1 \pm 0.3$ & $-4.2 \pm 0.1$ & $-0.37 \pm 0.01$ & $110 \pm 20 \mathrm{pM}^{11}$ & 91 \\
\hline$\underset{(\mathrm{PNP})^{d}}{\mathrm{DADMe}}$ & $-17.1 \pm 0.2$ & $-21.5 \pm 0.9$ & $-23.0 \pm 0.8$ & $-0.24 \pm 0.01$ & $16 \pm 1.4 \mathrm{pM}^{22}$ & 105 \\
\hline
\end{tabular}
$(\mathrm{PNP})^{d}$

${ }^{a}$ Enthalpy data observed from isothermal titrations of five MTAP ligands and one PNP ligand at three temperature values. ${ }^{b}$ The heat capacity associated with ligand binding. ${ }^{\mathcal{c}}$ The dissociation slow-onset, equilibrium dissociation constants $\left(K_{\mathrm{i}}^{*}\right)$ for transition-state analogues, measured at 25 ${ }^{\circ} \mathrm{C}$, are reported and referenced. ${ }^{d}$ The second set of $\Delta H$ values are for the second set of binding sites as described in the text. ${ }^{e}$ The $\mathrm{MT}$-tubercidin binding constant does not show slow-onset inhibition and was determined from the ITC tritation at $46{ }^{\circ} \mathrm{C}$. ${ }^{f}$ The total polar surface area of each compound was calculated using the sum of fragments method. ${ }^{28}$
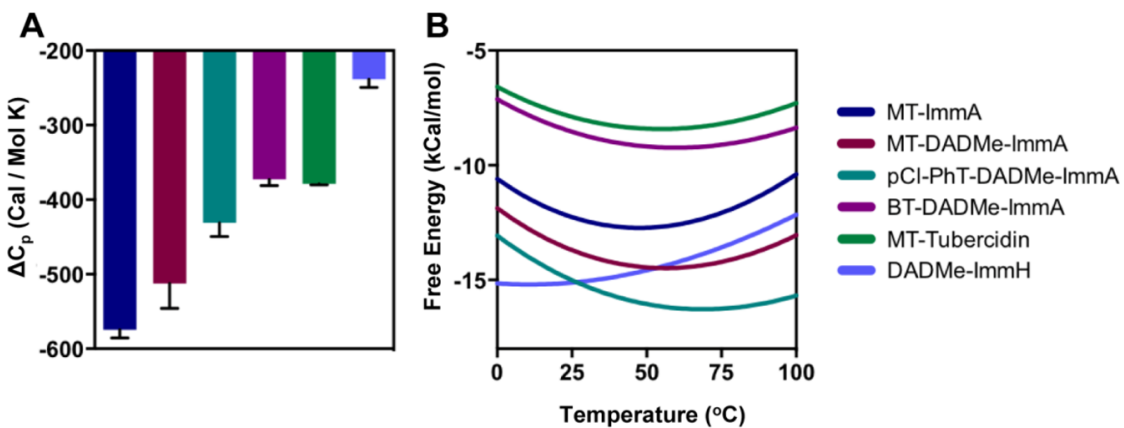

Figure 4. Heat capacity changes and optimal binding temperatures. (A) $\Delta C_{\mathrm{p}}$ values for each inhibitor binding to MTAP or for DADMe-ImmH binding to PNP. Numerical values are listed in Table 1. (B) Free energy of inhibitor binding to MTAP or PNP (for DADMe-ImmH) with respect to temperature. Optimal binding temperature is represented by the minimum value of these curves.

The heat capacity changes (Table 1, Figure 4) did not follow the expected trend of becoming increasingly negative with increasing ligand hydrophobicity, and an opposite trend was observed. The greatest heat capacity change was observed for binding of MT-ImmA, the MTAP transition-state analogue with the least hydrophobic character in its 5 '-subtituent. The smallest heat capacity change was observed for binding of $p$ Cl-PhTDADMe-ImmA and BT-DADMe-ImmA, the MTAP transitionstate analogues with the most hydrophobic 5 '-substituent. This pattern suggests different MTAP structural consequences beyond changes to the solvent accessible surface area and active site hydration. Differences in the number of rotatable bonds in each inhibitor cannot be responsible for the differences in $\Delta C_{p}$ as each of the MTAP inhibitors have the same number of rotatable bonds, with the exception of BT-DADMe-ImmA (See Figure 2B). Additionally, heat capacity changes were not correlated to inhibitor affinity or inhibitor polar surface area (Table 1). Thus, the dissociation constants for specific transition-state analogues and the heat capacity change upon ligand binding $\left(\Delta C_{p}\right)$ show potential to provide distinct information about the inhibitor similarity to the transition state structure.

Comparing 5'-Hydrophobic Substituent Effects. The $5^{\prime}$-substituents of BT-DADMe-ImmA and $p$ Cl-PhT-DADMeImmA are the most hydrophobic of the inhibitors (Figure 2). If the $\Delta C_{p}$ is dominated by the expulsion of water from the hydrophobic pocket of MTAP that accommodates these hydrophobic 5 '-substituents, the values for these two inhibitors would be expected to be similar. However, the $\Delta C_{\mathrm{p}}$ values binding these two analogues are significantly different (Table 1 , Figure 4). Previous work has shown that the average $\Delta C_{p}$ for each active site water molecule sequestration to be $-60 \pm 8 \mathrm{cal} /$ $\mathrm{mol} / \mathrm{K}^{29}$ Small differences in water binding are thus unlikely to explain the measured differences in $\Delta C_{\mathrm{p}}$ (Table 1, Figures 2, 4). Different $\Delta C_{\mathrm{p}}$ values for large hydrophobic $5^{\prime}$-functional groups suggest that active site water exclusion by those $5^{\prime}$ groups is not the deterministic factor for changes in $\Delta C_{p}$ values upon inhibitor binding. As mentioned above, these groups have similar flexibility (number of rotatable bonds), and this property is also unlikely to be sufficient to explain the differences in $\Delta C_{\mathrm{p}}$.

Comparing MTAP to PNP. Human PNP is specific for 6oxypurine nucleosides, while MTAP is specific for 6-amino-5'(alkyl-thio)purine nucleosides. DADMe-ImmH is a $\mathrm{pM}$ transition-state analogue of human PNP and does not bind to $\mathrm{MTAP}^{25}$ whereas MT-DADMe-ImmA is a pM inhibitor of MTAP and does not bind to PNP. However, the binding of DADMe-ImmH to human PNP is analogous to MT-DADMeImmA binding to MTAP, as both are close chemical transition state mimics for the phosphorolysis of inosine and MTA, respectively, in these closely related nucleoside phosphorylases. ${ }^{11,25}$ The binding of DADMe-ImmH to PNP results in a much different $\Delta C_{p}$ than for any of the inhibitors binding to MTAP (Table 1, Figure 4). Transition-state analogue binding to MTAP is dominated by entropic components, while binding of transition-state analogues to PNP is dominated by favorable enthalpy, the result of favorable active site hydrogen bonds and ionic interactions. The heat capacity difference between inhibitor binding to PNP and MTAP indicates different dynamic structural changes unique to MTAP-inhibitor complexes and predicts that transition-state analogue binding to PNP will show a distinct temperature sensitivity from MTAP (Figure 4B, Table 2). 
Table 2. Optimal Binding Temperature, Thermal Stability, and Structural Similarity of Enzyme-Inhibitor Complexes

\begin{tabular}{|c|c|c|c|}
\hline compound & $\begin{array}{l}\text { optimal } \\
\text { binding temp } \\
\left({ }^{\circ} \mathrm{C}\right)^{a}\end{array}$ & $\begin{array}{c}\text { melting } \\
\text { temperature } \\
\left(T_{\mathrm{m},}{ }^{\circ} \mathrm{C}\right)^{b}\end{array}$ & $\begin{array}{l}\text { crystallographic RMSD } \\
\text { relative to } 1 K 27(\AA)^{c}\end{array}$ \\
\hline AромТАР & N/A & $73.4 \pm 0.2$ & N/A \\
\hline MT-ImmA & $48 \pm 1$ & $86.1 \pm 0.2$ & N/A \\
\hline $\begin{array}{l}\text { MT-DADMe- } \\
\text { ImmA }\end{array}$ & $56 \pm 4$ & $94.7 \pm 0.5$ & 0.187 \\
\hline $\begin{array}{l}p \text { Cl-PhT- } \\
\text { DADMe- } \\
\text { ImmA }\end{array}$ & $69 \pm 3$ & $99.0 \pm 0.5$ & 0.175 \\
\hline $\begin{array}{l}\text { MT- } \\
\text { tubercidin }\end{array}$ & $55 \pm 0.2$ & $76.6 \pm 0.1$ & 0.177 \\
\hline $\begin{array}{l}\text { BT-DADMe- } \\
\text { ImmA }\end{array}$ & $61 \pm 1.5$ & $96.4 \pm 0.4$ & N/A \\
\hline $\begin{array}{l}\text { DADMe- } \\
\text { ImmH } \\
(\mathrm{PNP})\end{array}$ & $11 \pm 0.5$ & $\mathrm{~N} / \mathrm{A}$ & $\mathrm{N} / \mathrm{A}$ \\
\hline
\end{tabular}

${ }^{a}$ Optimal binding temperatures were calculated from eqs 6 and 7 using the parameters of Table $1 .{ }^{b}$ The thermal stability of MTAP complexes was determined by a loss of structural features by $\mathrm{CD}$ analysis as a function of temperature. $T_{\mathrm{m}}$ is the temperature midpoint for the loss of structural features. ${ }^{c} \mathrm{X}$-ray crystallographic analysis indicated small RMSD differences for the aligned structures relative to MTAP-MTImmA (Figure 6).

Despite their common trimeric structures, subunit interactions differ for PNP and MTAP. In PNP titrations, filling of the second site gave a different heat capacity than the filling of the first site, while sequential site fillings for MTAP are independent. Unlike MTAP, PNP is completely inhibited when the first of the three active sites is filled with inhibitor. ${ }^{25}$

Determination of Optimal Binding Temperatures. Heat capacity and related thermodynamic values can be used to predict the optimal binding temperature for each ligand. The enthalpic and entropic components of ligand binding change at different rates when the process carries a nonzero heat capacity change. Reference values for $\Delta H$ and $\Delta S$ of binding at $25^{\circ} \mathrm{C}$ were used, as ligand dissociation constants have been defined through kinetic experiments. ${ }^{11,12,17}$ The optimal binding temperature was determined by solving eqs 6 and 7 for the value of $T$ at the temperature where $\Delta S=0$ to find the point when $\Delta G$ is at its minimum (see Figure $4 \mathrm{~B}$, Table 2, Figure S2). The MTAP analogues had optimal binding temperatures of 48 to $69{ }^{\circ} \mathrm{C}$, far above physiological temperatures. These differ dramatically from human PNP, where low temperatures favor tight binding, and the optimal binding temperature is $11^{\circ} \mathrm{C}$ for DADMe-ImmH (Table 2, Figure 4, eq 8).

Thermal Stability of MTAP Ligand Complexes. Optimal inhibitor binding at supra-physiological temperatures is an unusual property for enzymes and infers ligand-induced stability at elevated temperatures. Variable temperature circular dichroism (CD) measurements were used to determine the thermal stability of MTAP complexes. Protein unfolding temperature $\left(T_{\mathrm{m}}\right)$ was measured by monitoring $\mathrm{CD}$ absorbance at $222 \mathrm{~nm}$ at varying temperatures. ${ }^{30}$ MTAP thermal stability was remarkably high, with apoMTAP $T_{\mathrm{m}}$ occurring at $74.3^{\circ} \mathrm{C}$. With inhibitors bound to MTAP, the melting temperature increased. The substrate analogue MT-tubercidin increased the $T_{\mathrm{m}}$ modestly to $76.6{ }^{\circ} \mathrm{C}$ (Table 2). More tightly bound species caused stabilization of enzymatic structure with $T_{\mathrm{m}}$ values of 86.1, 94.7, and $99^{\circ} \mathrm{C}$ for MT-ImmA, MT-DADMe-ImmA, and $p \mathrm{Cl}$ PhT-DADMe-ImmA, respectively. With BT-DADMe-ImmA or
pCl-PhT-DADMe-ImmA bound to MTAP, the protein had not fully unfolded when samples began to boil (near $100{ }^{\circ} \mathrm{C}$ ).

Melting temperatures of the MTAP-inhibitor complexes (Table 2, Figure S3) correlated with inhibitor binding constants, ${ }^{11,12}$ but not with the observed heat capacity change. The increased stability with bound transition-state analogues demonstrates induced stability against protein unfolding in the MTAP-ligand complex.

Molecular Dynamics of Protein-Inhibitor Complexes. The dynamic structure of MTAP in the presence of transitionstate analogues was compared to the apoenzyme to see how the MTAP-ligand structures differed in terms of protein conformational flexibility. We conducted $40 \mathrm{~ns} \mathrm{MD}$ simulations at $300 \mathrm{~K}$ and estimated the average mass-weighted Root Mean Square Fluctuation (RMSF) values for all protein residues over the course of the simulation. ${ }^{31}$ RMSF values of MTAP complexed to MT-ImmA and $p$ Cl-PhT-DADMe-ImmA were compared relative to RMSF values for apoMTAP. MD simulations revealed that despite MT-ImmA binding less tightly than $p \mathrm{Cl}-\mathrm{PhT}$ DADMe-ImmA, the $p$ Cl-PhT-DADMe-ImmA bound structure more closely resembled the apoMTAP structure. However, these differences were small with overall RMSF values for apoMTAP, MT-ImmA-bound, and the $p$ Cl-PhT-DADMe-ImmA-bound structures giving total RMSFs of $278 \AA$, $283 \AA$, and $285 \AA$, respectively ( $\Sigma|\mathrm{C} a \mathrm{RMSF}|)$. These values are remarkable in suggesting that MTAP complexed with these inhibitors are slightly more flexible than the apo structure, contrary to normal expectations for interactions of enzymes with their transitionstate analogues.

As low frequency modes in globular proteins have been estimated to contribute over $80 \%$ of the value to the $\Delta C_{p}$ term, ${ }^{32,33}$ this increased motion agrees with the measured $-\Delta C_{p}$ values. A remarkable feature in both $\mathrm{MT}$-ImmA and $p \mathrm{Cl}-\mathrm{PhT}$ DADMe-ImmA structures is residue Thr168, with a large negative RMSG relative to the apo structure. This residue is found at the hinge region beginning a $\beta$-sheet motif near the enzyme's active site and thus becomes stabilized in both structures (see Figures 5 and 6).

Crystal Structures of MTAP Ligand Complexes. We solved crystal structures of the MTAP-PO ${ }_{4}$ complex with MTDADMe-ImmA, PrT-ImmA, and MT-tubercidin and the MTAP-Cl complex (from a $\mathrm{NaCl}$ mother liquor) with BTDADMe-ImmA. They were compared to the structures previously solved for $\mathrm{MTAP}-\mathrm{PO}_{4}$ bound to MT-ImmA and pCl-PhT-DADMe-ImmA. ${ }^{17,34}$

MTAP with BT-DADMe-ImmA-bound was crystallized from a high-salt precipitant $(3 \mathrm{M} \mathrm{NaCl})$, resulting in the exclusion of phosphate from the active site and replacement by a chloride anion. Bound chloride caused relaxation of the active site region for this complex and altered the trimer packing, preventing direct comparison of this to other structures. Alignment of the remaining structures to that of $\mathrm{MTAP}-\mathrm{PO}_{4}$ with $\mathrm{MT}-\mathrm{ImmA}$ bound (PDB ID: 1K27) permitted the determination of RMSDs between closely related structures. Despite significant differences in heat capacities for these five structures, no substantial structural differences were observed (e.g., Figure 6). The largest RMSD difference in $\mathrm{C} \alpha$ peptide backbone positions between the structures was $<0.19 \AA$ (Table 2). Analysis of ordered water molecules in the active site did not inform on the observed differences in heat capacity. Thus, protein structural changes observed in the solid state by X-ray crystallography do not appear to be responsible for the differences in enzyme-inhibitor heat capacity changes. Nonetheless, there were some interesting 

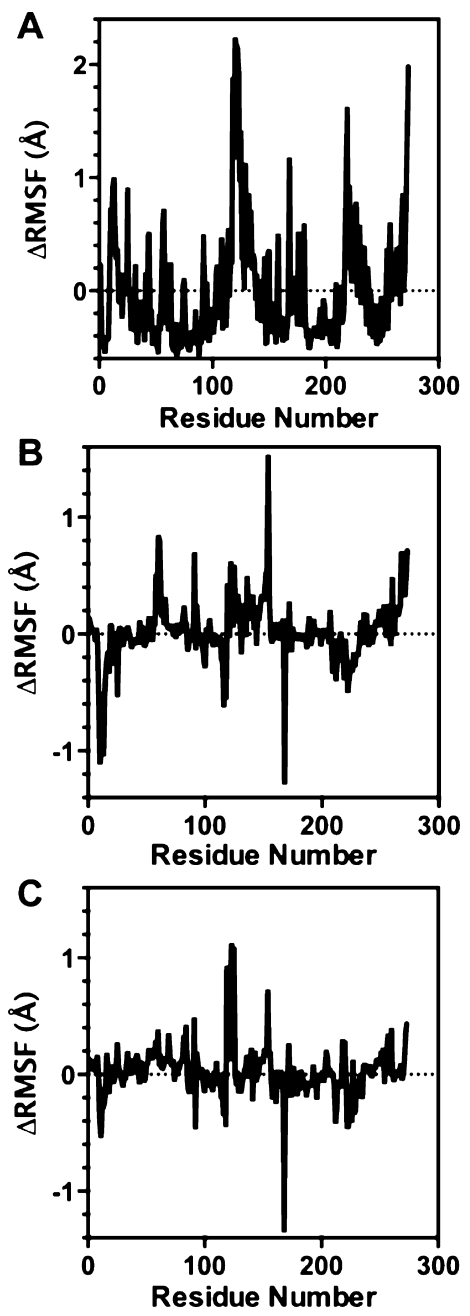

Figure 5. Molecular dynamics of TS analogue binding to MTAP. (A) The $\triangle$ RMSF for apoMTAP structure relative to its average residue RMSF. Loop and hinge regions at the protein surface show especially high flexibility. The $\triangle$ RMSF of (B) MT-ImmA-bound MTAP and (C) pCl-PhT-DADMe-ImmA-bound MTAP relative to apoMTAP show increased overall dynamic flexibility for TS analogue bound structures relative to the apo structure (see text).

features. All structures feature a chloride ion at the center of the homotrimer, which is hydrogen-bonded to the three symmetryrelated Arg116 side chains and a water molecule. In the structure with MT-DADMe-ImmA there is an ordered PEG fragment (modeled as $\mathrm{PDB}$ ligand $2 \mathrm{PE}$ ) that appears to chelate a magnesium ion in a crown-ether-like interaction. This moiety is located between stacks of trimers. The distance between trimers is similar in other MTAP structures but the magnesium complex opens a space to solvent. As magnesium is absent in the kinetic and ITC experiments, its presence in the crystal structures does not explain heat capacity differences.

Heat Capacity for MTAP Chemical Kinetics. Pre-steadystate kinetic experiments using 2-amino- 5 '-methylthioadenosine showed that MTAP chemistry is strongly temperature dependent and nonlinear, demonstrating a change in heat capacity for transition-state formation $\left(\Delta C_{\mathrm{p}}^{\ddagger}\right.$; Figure 7$)$. Pre-steady-state kinetic data taken at multiple temperatures were fitted to a modified version of the Eyring equation (SI eq 8) to determine the heat capacity for formation of the transition state by MTAP. The $\Delta C_{\mathrm{p}}^{\ddagger}$ was determined to be $-558 \pm 26 \mathrm{cal} / \mathrm{mol} / \mathrm{K}$, which is most similar to the $\Delta C_{\mathrm{p}}$ values for binding MT-ImmA and MT-
DADMe-ImmA. On the basis of transition-state analysis for the phosphorolysis of MTA, MT-DADMe-ImmA is the analogue most closely representing the geometric and molecular electrostatic potential of the MTAP transition state structure of MTAP. ${ }^{10}$ The increased affinity of pCl-PhT-DADMe-ImmA for MTAP therefore comes not from a closer similarity to the transition state but from the added hydrophobic interaction of the $p$-Cl-phenyl group in the 5 -substituent binding region of the MTAP catalytic site. Thus, comparison of $\Delta C_{\mathrm{p}}^{\ddagger}$ values for catalysis and $\Delta C_{\mathrm{p}}$ values for inhibitor binding offer a distinct parameter for evaluating TS analogue similarity to the TS.

\section{CONCLUSION}

Investigation of the temperature dependence of ligand binding adds insight into protein-ligand interactions by allowing the determination of $\Delta C_{p}$. The thermodynamic parameter, $\Delta C_{p}$, quantifies the temperature-dependence of $\Delta H$ and $\Delta S$ and thus, the temperature dependence of $\Delta G$ for the interaction. Further, $\Delta C_{\mathrm{p}}$ reports on the redistribution of vibrational modes for the protein, solvent, and catalytic site contents upon ligand binding. Broadly, contributions to $\Delta C_{p}$ can be divided between solvation/ desolvation effects and redistribution of protein vibrational modes. If solvation were the dominant factor in ligand binding, we would expect to see decreasing values of $\Delta C_{p}$ for increasing hydrophobicity, and this is not the case for the experimental data. Thus, the results imply that substitutents of increasing hydrophobicity facilitate increasing populations of low frequency protein vibrational modes upon binding, when compared to MTImmA binding.

Transition-state analogues designed from an experimentally determined transition-state structure approximate, but can never equal, the nonequilibrium properties of an actual transition state. Here, we explore several transition-state mimics and compare their thermodynamic binding quantities to substrate analogue binding. Ligand binding affinity, similarity of electrostatic maps to the TS model from isotope effects, and crystallographic analyses are indices for the similarity of analogues to the TS. However, we conclude that heat capacity is also a useful parameter to rank TS analogues for similarity to the TS structure. While a $\Delta C_{\mathrm{p}}$ comparison of TS analogues may not necessarily be useful in pharmaceutical efficacy, it is valuable in comparing the various TS analogues to the chemical kinetic TS energetics. Comparison suggests similar $\Delta C_{\mathrm{p}}$ values indicate similarity to the TS.

\section{MATERIALS AND METHODS}

Chemical Synthesis. Transition-state analogues of human 5'methylthioadenosine phosphorylase (MTAP) were synthesized as previously reported ${ }^{9,10}$ and generously provided by the Ferrier Research Institute, Victoria University of Wellington, New Zealand.

Human MTAP Expression and Purification. Plasmid construction for expression of human MTAP was previously reported. ${ }^{14}$ Plasmids containing E. coli BL21(DE3) cells were grown for $14 \mathrm{~h}$ at 37 ${ }^{\circ} \mathrm{C}$ in $25 \mathrm{~mL}$ of LB broth containing $100 \mu \mathrm{g} / \mathrm{mL}$ ampicillin. Starter culture was then inoculated into $1 \mathrm{~L}$ of the same media and incubated at $37{ }^{\circ} \mathrm{C}$ until an $\mathrm{OD}_{600}$ between 0.6 and 0.8 was reached. MTAP expression was induced with $1 \mathrm{mM} \mathrm{IPTG}$ for $4 \mathrm{~h}$ at $37^{\circ} \mathrm{C}$. The resulting cells were extracted via centrifugation at $4000 \mathrm{~g}$ for $25 \mathrm{~min}$.

Cells were resuspended in cell lysis buffer containing $300 \mathrm{mM} \mathrm{NaCl}$, $50 \mathrm{mM} \mathrm{K}_{2} \mathrm{PO}_{4}$, and $10 \mathrm{mM}$ imidazole at $\mathrm{pH} 8.0$, and disrupted by sonication at $30 \%$ amplitude for $10 \mathrm{~min}$. Cell debris was removed by three rounds of centrifugation at $25000 \mathrm{~g}$ for $20 \mathrm{~min}$, discarding isolated debris. Clarified cell lysate was purified using $5 \mathrm{~mL}$ of Ni-NTA resin. The column was equilibrated with $10 \mathrm{~mL}$ of lysis buffer prior to loading the 


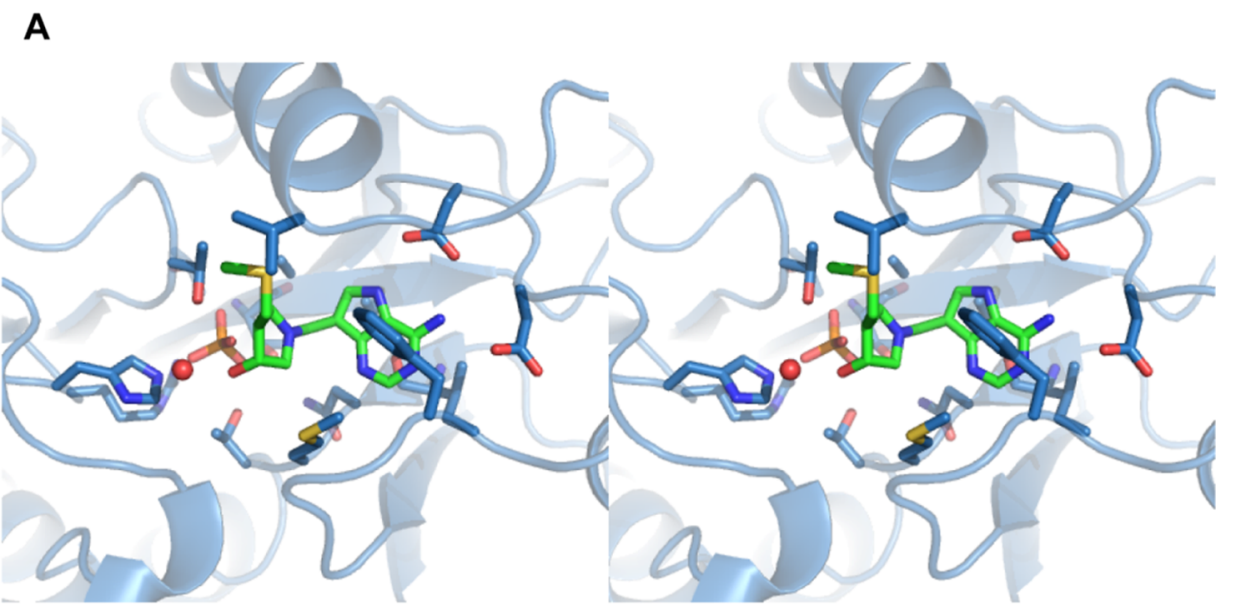

B

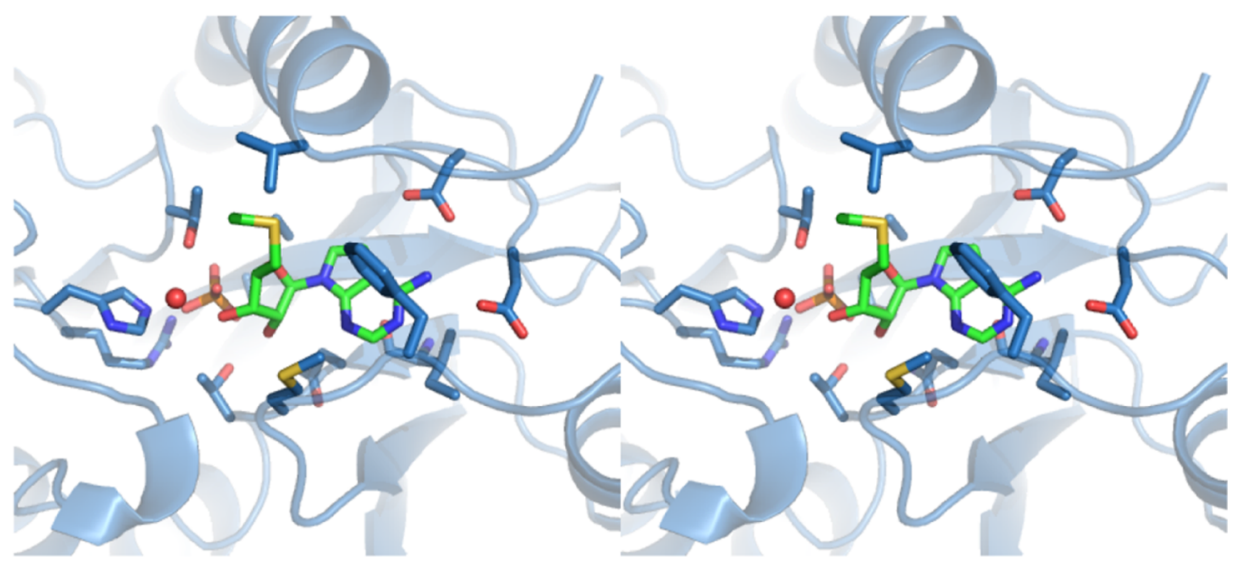

Figure 6. Crystal structures of MTAP-ligand complexes. A stereoview of MTAP in complexes with (A) MT-DADMe-ImmA and (B) MT-tubercidin. Structures show closely related structural features despite the difference in $\Delta C_{\mathrm{p}}$ of inhibitor binding values. Inhibitor carbons are green. The red sphere is an ordered water molecule near bound phosphate (orange).

A<smiles>[R5]c1nc(N)c2ncn(C(O)C3OC(C)(C)CC3(C)O)c2n1</smiles>

B

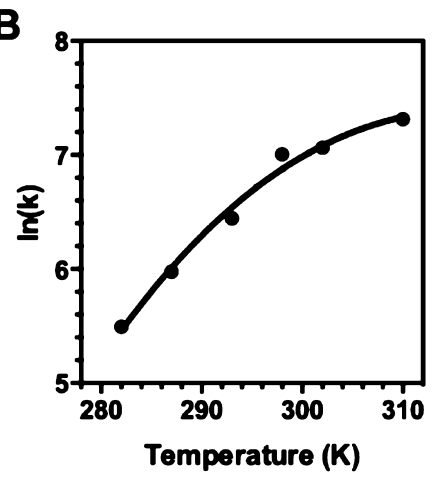

Figure 7. MTAP has a negative $\Delta C_{\mathrm{p}}^{\ddagger}$ for presteady-state kinetics. (A) Phosphorolysis of 2-amino-MTA $\left(\mathrm{R}=\mathrm{NH}_{2}\right)$ was measured under pre-steady-state kinetics at multiple temperatures by the formation of 2,6-diaminopurine, a fluorescent product. The rate of product formation $(\ln (k))$ is in arbitrary units of fluorescence. (B) The relationship between rate and temperature is nonlinear, establishing a nonzero $\Delta C_{\mathrm{p}}^{\ddagger}$. A fit to eq 8 gave $\Delta C_{\mathrm{p}}^{\ddagger}=-558 \pm 26 \mathrm{cal} /$ $\mathrm{mol} / \mathrm{K}$.

cell lysate. The column was washed with $20 \mathrm{~mL}$ of wash buffer containing $300 \mathrm{mM} \mathrm{NaCl}, 50 \mathrm{mM} \mathrm{K}_{2} \mathrm{PO}_{4}$, and $80 \mathrm{mM}$ imidazole, at $\mathrm{pH}$ 8.0. Protein was eluted with $20 \mathrm{~mL}$ of elution buffer containing $300 \mathrm{mM}$ $\mathrm{NaCl}, 50 \mathrm{mM} \mathrm{K}_{2} \mathrm{PO}_{4}$, and $250 \mathrm{mM}$ imidazole at a $\mathrm{pH}$ of 8.0. Purity was assessed by SDS-PAGE, with protein fractions containing $~ 99 \%$ purity being pooled.

Human MTAP copurifies with bound adenine present in the active site. Bound adenine was removed by dialysis against an external buffer containing charcoal. MTAP was treated in dialysis cassettes $(10 \mathrm{kDa}$ MWCO) and dialyzed against $100 \mathrm{mM} \mathrm{K}_{2} \mathrm{PO}_{4}$ and $0.5 \% \mathrm{v} / \mathrm{v}$ activated charcoal at a $\mathrm{pH}$ of 7.4 overnight. Quantitation of enzyme-bound adenine before and after charcoal dialysis was assessed by denaturing protein with $10 \% \mathrm{v} / \mathrm{v}$ perchloric acid, removing denatured protein by centrifugation and determination of adenine concentration via spectrophotometry (extinction coefficient $\varepsilon_{260}=13.0 \mathrm{mM}^{-1} \mathrm{~cm}^{-1}$ ).

Adenine-free MTAP was dialyzed against $100 \mathrm{mM} \mathrm{K}_{2} \mathrm{PO}_{4}$ and $2 \mathrm{mM}$ $\mathrm{DTT}$ at a $\mathrm{pH}$ of 7.4 overnight and concentrated to $\sim 250 \mu \mathrm{M}$. Apo enzyme and the dialysate were used for ITC studies.

ITC Studies. ITC studies were conducted using a VP-ITC MicroCalorimeter. Transition-state analogue solutions were prepared 
by dissolving inhibitor salts into filtered dialysate. Protein and inhibitor solutions were filtered and degassed for $15 \mathrm{~min}$ using a Microcal Thermovac and loaded into a $1.46 \mathrm{~mL}$ sample cell and $280 \mu \mathrm{L}$ injection syringe, respectively. Final protein concentrations ranged from 25 to 50 $\mu \mathrm{M}$. Inhibitor solutions were titrated into protein solution over 30 to 35 injections of $8 \mu \mathrm{L}$ over $8 \mathrm{~s}$ with a $180 \mathrm{~s}$ equilibration period between injections. Titrations of inhibitors (Figure 1) into protein solutions were conducted at 20,37 , and $46^{\circ} \mathrm{C}$. Dilution energies associated with both the inhibitor dilution and protein dilution were measured to correct for any nonbinding energy sources. The resulting data were fit to a model of one distinct binding site with the exception of the PNP titration with DADMe-ImmH and the MTAP titration with BT-DADMe-ImmA, which were fit to a model of two distinct binding sites.

ITC Data Processing. ITC data were fit using equations from Origin7 software. Free energy $(\Delta G)$ values for each titration of slow onset inhibitors were calculated from eq 1 using reference $k_{\mathrm{i}}{ }^{*}$ values, ${ }^{11,12}$ as dissociation constants for tight-binding inhibitors cannot be measured accurately via ITC experiments alone. ITC data were used to determine the free energy of binding for MT-tubercidin, where the dissociation constant was determined from ITC data as a direct reciprocal of the calculated association constant (Figure S1). Entropy $(\Delta S)$ values were determined from eq 2 .

$$
\begin{aligned}
& \Delta G=-R T \ln K_{\mathrm{i}}^{*} \\
& \Delta G=\Delta H-T \Delta S
\end{aligned}
$$

Eqs 3 and 4 were used to determine the total heat content $(Q)$ in the cell volume $\left(V_{0}\right)$ for a single set of sites and two sets of sites, respectively. Eq 5 was used to determine the total heat released $\left(\Delta Q_{i}\right)$ from the $i$ th injection in each of the two models. In eqs $3-5, n$ represents the number of sites, $\Theta$ represents the fraction of sites occupied by a ligand, and $\Delta H$ represents the molar enthalpy associated with inhibitor binding.

$$
\begin{aligned}
& Q=n \Theta M_{\mathrm{t}} \Delta H V_{0} \\
& Q=M_{\mathrm{t}} V_{0}\left(n_{1} \Theta_{1} \Delta H_{1}+n_{2} \Theta_{2} \Delta H_{2}\right) \\
& \Delta Q_{i}=Q_{i}+\frac{d V_{i}}{V_{0}}\left(\frac{Q_{i}+Q_{i-1}}{2}\right)-Q_{i-1}
\end{aligned}
$$

Determination of Optimal Ligand Binding Temperatures. ITC studies were conducted at 20,37 , and $46^{\circ} \mathrm{C}$ to quantify the change in heat capacity $\left(\Delta C_{\mathrm{p}}\right)$ of the protein-ligand complex relative to the individual components. Enthalpy values from each ITC experiment were analyzed via a linear regression, the slope of which corresponds to the observed change in heat capacity in accordance with eq 6, where $\Delta H_{0}$ represents the enthalpy of ligand binding at temperature $T_{0}$.

$$
\begin{aligned}
& \Delta H=\Delta H_{T_{0}}+\Delta C_{\mathrm{p}}\left(T-T_{0}\right) \\
& \Delta S=\Delta S_{T_{0}}+\Delta C_{\mathrm{p}}\left(\ln \frac{T}{T_{0}}\right) \\
& T_{\text {opt }}=T_{0} / \mathrm{e}^{\left(\Delta S_{T_{0}} / \Delta C_{\mathrm{p}}\right)}
\end{aligned}
$$

Optimal binding temperature was then determined by finding the temperature value $(T)$ at which the $\Delta G$ value (eqs $2,6,7,8$ ) was at its minimum. ${ }^{23,24}$

Thermal Stability of Protein-Ligand Complexes. The melting temperatures of apoMTAP and MTAP-inhibitor complexes were determined through variable temperature circular dichroism spectroscopy measurements (Figure 1). ${ }^{30}$ MTAP was dialyzed against $10 \mathrm{mM}$ $\mathrm{K}_{2} \mathrm{PO}_{4}$ at a $\mathrm{pH}$ of 7.4 and diluted to $2 \mu \mathrm{M}$. Samples of apoMTAP as well as MTAP in complex with each ligand were heated from 25 to $100^{\circ} \mathrm{C}$ at a rate of $1^{\circ}$ per minute with a $\mathrm{CD}$ measurement taken at $222 \mathrm{~nm}$ every $2^{\circ}$. Melting temperatures of enzyme and enzyme ligand complexes were determined by plotting molar ellipticity values vs temperature as a fourparameter variable slope nonlinear regression to determine the inflection points of the melting curves $\left(T_{\mathrm{m}}\right)$.

Molecular Dynamics Simulations of MTAP Complexes. Coordinates for the MTAP protein and the transition-state analogues were extracted from the crystal structures of MTAP in complex with MT-ImmA (PDB 1K27) and pCl-PhT-DADMe-ImmA (PDB 3OZC). The coordinates for the simulation of MTAP without bound ligand were taken from the crystal structure of the latter complex, with the ligand removed. All water molecules in the crystal structures were removed, and three missing loop residues in the MTAP protein complexed with MT-ImmA were added into the PDB using MODELER. ${ }^{35}$ Hydrogen atoms and other missing coordinates were added using the LEAP program. Atomic partial charges for the ligands were derived using the RESP protocol ${ }^{36}$ in Gaussian 09 and the HF/6-31G* level of theory. Parameters for the ligands were then derived using ANTECHAMBER ${ }^{37}$ and the Generalized AMBER Force Field (GAFF). ${ }^{38}$ The remaining parameters were based on the AMBER99SB force field. ${ }^{39}$ The protein was placed in an octahedral box of TIP3P water with a $10 \AA$ buffer between the protein and the box. $\mathrm{Na}^{+}$counterions were added to neutralize the box. All simulations were conducted using periodic boundary conditions and a 2 fs time step. The box was first minimized with $500 \mathrm{kcal} / \mathrm{mol} / \AA^{2}$ restraints on the protein and ligand atoms, using 500 cycles of steepest descent minimization followed by 1500 cycles of conjugate gradient minimization. The box was then heated to $300 \mathrm{~K}$ over $20 \mathrm{ps}$ in the NVT ensemble with $10 \mathrm{kcal} / \mathrm{mol} / \AA^{2}$ restraints on the protein and ligand. Temperature control was achieved using a Langevin thermostat with a collision frequency of $1.0 \mathrm{ps}^{-1}$. The restraints were removed, and then 200 ps of NPT dynamics, using the Berendstat barostat with a $2.0 \mathrm{ps}$ relaxation time to maintain the pressure at $1 \mathrm{bar}$, were run to equilibrate the density of the box. Short-range electrostatic interactions and van der Waals interactions were computed to a cutoff of $12 \AA$, and long-range electrostatic interactions were computed using the Particle Mesh Ewald algorithm. ${ }^{40}$ Hydrogen bonds were constrained using SHAKE. ${ }^{41}$

Following preparation of the simulation box, the remaining simulations were run in the NVT ensemble. The first 2 ns of simulation were used as equilibration time, followed by $40 \mathrm{~ns}$ production runs of each the apoMTAP structure and the MTAP protein in complex with MT-ImmA or $p$ Cl-PhT-DADMe-ImmA.

Determination of MTAP Heat Capacity via Temperature Sensitivity of MTAP Kinetics. Pre-steady-state kinetics were characterized using 2-amino-5'-methylthioadenosine as an alternative substrate. Phosphorolysis generates the fluorescent 2,6-diaminopurine product to allow accurate quantitation of product formation. ${ }^{42}$ Presteady-state experiments were carried out on an Applied Photophysics model SX20 stopped-flow instrument, which has a dead time of approximately $2 \mathrm{~ms}$. Each experiment was an average of at least 12 measurements under identical conditions.

$$
\begin{aligned}
\ln k= & \ln \frac{k_{\mathrm{b}} T}{h}-\left[\frac{\Delta H_{T_{0}}^{\ddagger}+\Delta C_{\mathrm{p}}^{\ddagger}\left(T-T_{0}\right)}{R T}\right] \\
& +\left[\frac{\Delta S_{T_{0}}^{\ddagger}+\Delta C_{\mathrm{p}}^{\ddagger}\left(\ln T-\ln T_{0}\right)}{R}\right]
\end{aligned}
$$

Reactions were monitored by measuring the fluorescence at $345 \mathrm{~nm}$ given incident light at $280 \mathrm{~nm}$. Experiments were conducted by $60 \mu \mathrm{L}$ coinjections of MTAP and substrate in $100 \mathrm{mM}$ potassium phosphate and $1 \mathrm{mM} \mathrm{DTT}$, at $\mathrm{pH}=7.4$ at varying concentrations of substrate. The resulting data were fit to a modified version of the Eyring equation (eq 8) to determine the $\Delta C_{\mathrm{p}}$.

Cocrystallization of Human MTAP with Various Inhibitors. HsMTAP was concentrated to $15 \mathrm{mg} \mathrm{mL}^{-1}$ and incubated with 2 equiv of the respective inhibitors, with the $\mathrm{N}$-terminal $\mathrm{His}_{6}$ tag and TEVprotease cleavage site intact. All crystallization experiments were performed at $22{ }^{\circ} \mathrm{C}$ using the sitting drop vapor diffusion technique. Rod-shaped crystals $(0.04 \mathrm{~mm} \times 0.04 \mathrm{~mm} \times 0.40 \mathrm{~mm})$ of $H s$ MTAP. MT-tubercidin were obtained over 2 days using $0.2 \mathrm{M}$ magnesium chloride and 20\% (w/v) PEG 3350. Rod-shaped crystals $(0.02 \mathrm{~mm} \times$ $0.03 \mathrm{~mm} \times 0.40 \mathrm{~mm}$ ) of HsMTAP.PrT-ImmA and rod-shaped crystals $(0.06 \mathrm{~mm} \times 0.06 \mathrm{~mm} \times 0.27 \mathrm{~mm})$ of $H s$ MTAP.MT-DADME-ImmA were obtained over 1 week, using $0.2 \mathrm{M}$ magnesium chloride, $0.1 \mathrm{M}$ sodium citrate:citric acid ( $\mathrm{pH} 5.5$ ), and 40\% (v/v) PEG 400. Block- 
shaped crystals $(0.10 \mathrm{~mm} \times 0.14 \mathrm{~mm} \times 0.18 \mathrm{~mm})$ of $H s$ MTAP.BTDADMe-ImmA were obtained over 3 weeks using $3 \mathrm{M}$ sodium chloride and $0.1 \mathrm{M}$ sodium acetate ( $\mathrm{pH} 4.5)$.

Crystallography Data Collection and Processing. The HsMTAP crystals with MT-tubercidin and PrT-ImmA bound were transferred to a cryoprotectant solution containing $20 \%(\mathrm{v} / \mathrm{v})$ glycerol and the respective mother liquors $[80 \%(\mathrm{v} / \mathrm{v})]$ prior to being flashcooled in liquid nitrogen. The two other crystals were directly flashcooled in liquid nitrogen. Diffraction data for the MT-DADME-ImmAand PrT-ImmA-bound HsMTAP crystals were collected with $1.075 \AA$ wavelength radiation at the X29A beamline (Brookhaven National Laboratory, Upton, NY) on an ADSC Q315 CCD X-ray area detector to 1.80 and $1.50 \AA$ resolution, respectively. Diffraction data for the MTtubercidin- and BT-DADMe-ImmA-bound HsMTAP crystals were collected with $0.9793 \AA$ a wavelength radiation at the LRL-CAT beamline (Argonne National Laboratory, Argonne, IL) on a Rayonix $225 \mathrm{HE}$ CCD detector to 1.75 and $1.96 \AA$ resolution, respectively. Diffraction intensities were integrated and scaled with Denzo and Scalepack ${ }^{43}$ or XDS. ${ }^{44}$ The diffraction data statistics are summarized in Table S1.

Crystal Structure Determination. The structures were determined by molecular replacement with Molrep, ${ }^{45}$ using a single monomer from the previously published structure of HsMTAN. methylthio-Immucillin-A (PDB entry 1K27) as a search model. For all structures, the refinement of the initial solution and subsequent refinements were conducted using a restrained refinement performed with Refmac, ${ }^{46}$ using all data between $25.0 \AA$ and the respective highresolution cutoffs. The BT-DADMe-ImmA-bound structure was refined using additional TLS parameters, as well as automatically generated local NCS restraints. Manual model rebuilding was conducted using Coot. ${ }^{47}$ Difference Fourier maps calculated with $F_{\text {obs }}-F_{\text {calc }}$ coefficients revealed ordered water molecules and a strong unambiguous density difference, corresponding to the respective inhibitors. The coordinates for three of the inhibitors were present in the Coot monomer library, having monomer codes MTH for methylthiotubercidin, TDI for MT-DADMEImmA, and BIG for BT-DADMe-ImmA. The restraints for inhibitor 5'propylthio-Immucillin-A were generated using JLigand. ${ }^{48}$ Water molecules with proper hydrogen bonding coordination and electron densities greater than 1 RMSD and 3 RSMDs in maps calculated with $2 F_{\text {obs }}-F_{\text {calc }}$ and $F_{\text {obs }}-F_{\text {calc }}$ coefficients, respectively, were included in the model. In most of the structures, residues $\mathrm{Ala}(9)$ to $\mathrm{Leu}(280)$ or Pro(281) were sufficiently ordered to be built, with the $\mathrm{His}_{6} /$ cleavage tag unable to be modeled. The exception was the BT-DADMe-ImmAbound structure, in which residues between $\operatorname{Arg}(63)$ and $\operatorname{His}(65)$ were missing or disordered. Additionally, several residues at the beginning of one of the three chains in this structure was able to modeled, from $\mathrm{His}(-8)$ to $\mathrm{Gly}(4)$. Several residues in each structure were modeled with alternate conformations. The HsMTAP-MT-tubercidin structure was refined to an $R_{\text {cryst }}$ of $17.0 \%$ and an $R_{\text {free }}$ of $18.4 \%$, the HsMTAP.PrTImmA structure to an $R_{\text {cryst }}$ of $15.9 \%$ and an $R_{\text {free }}$ of $16.5 \%$, the $H s$ MTAP. MT-DADMe-ImmA structure to an $R_{\text {cryst }}$ of $16.2 \%$ and an $R_{\text {free }}$ of $18.3 \%$, and the $H s$ MTAP-BT-DADMe-ImmA structure to an $R_{\text {cryst }}$ of $19.0 \%$ and an $R_{\text {free }}$ of $21.7 \%$. Analysis of the structures in Coot revealed good stereochemistry with no residues falling into the disallowed regions of the Ramachandran plot in any of the structures, except Thr18 in the HsMTAP-BT-DADMe-ImmA structure. The refinement statistics are listed in Table S1.

\section{ASSOCIATED CONTENT}

\section{S Supporting Information}

The Supporting Information is available free of charge on the ACS Publications website at DOI: 10.1021/acschembio.6b00885.

Supporting Information Figures 1-3 and Supporting Information Table 1 (PDF)

\section{AUTHOR INFORMATION}

\section{Corresponding Author}

*Phone: 718-430-2813. E-mail: vern.schramm@einstein.yu.edu.
ORCID

Vern L. Schramm: 0000-0002-8056-1929

Notes

The authors declare no competing financial interest.

\section{ACKNOWLEDGMENTS}

This work was supported by research grant R01 CA135405 and training grant T32 GM007288 from the National Institutes of Health. Crystallographic data for this study were measured at beamline X29A of the National Synchrotron Light Source. Financial support comes principally from the Offices of Biological and Environmental Research and of Basic Energy Sciences of the U.S. Department of Energy, and from the National Center for Research Resources (P41RR012408) and the National Institute of General Medical Sciences (P41GM103473) of the National Institutes of Health. This research also used resources of the Advanced Photon Source, a U.S. Department of Energy (DOE) Office of Science User Facility operated for the DOE Office of Science by Argonne National Laboratory under Contract No. DE-AC0206CH11357. Use of the Lilly Research Laboratories Collaborative Access Team (LRL-CAT) beamline at Sector 31 of the Advanced Photon Source was provided by Eli Lilly Company, which operates the facility.

\section{REFERENCES}

(1) Tabor, C. W., Tabor, C. W., Tabor, H., and Tabor, H. (1984) Polyamines. Annu. Rev. Biochem. 53, 749-790.

(2) Albers, E. (2009) Metabolic characteristics and importance of the universal methionine salvage pathway recycling methionine from 5methylthioadenosine. IUBMB Life 61, 1132-1142.

(3) Valaperta, R., Rizzo, V., Lombardi, F., Verdelli, C., Piccoli, M., Ghiroldi, A., Creo, P., Colombo, A., Valisi, M., Margiotta, E., Panella, R, and Costa, E. (2014) Adenine phosphoribosyltransferase (APRT) deficiency: identification of a novel nonsense mutation. BMC Nephrol. $15,102$.

(4) Wallace, H. M., Fraser, A. V., and Hughes, A. (2003) A perspective of polyamine metabolism. Biochem. J. 376, 1-14.

(5) Meyskens, F. L., and Gerner, E. W. (1995) Development of difluoromethylornithine as a chemoprevention agent for the management of colon cancer. J. Cell. Biochem. 59, 126-131.

(6) Battaglia, V., DeStefano Shields, C., Murray-Stewart, T., and Casero, R. A. (2014) Polyamine catabolism in carcinogenesis: Potential targets for chemotherapy and chemoprevention. Amino Acids 46, 511519 .

(7) Lubin, M., and Lubin, A. (2009) Selective killing of tumors deficient in methylthioadenosine phosphorylase: A novel strategy. PLoS One 4, e5735.

(8) Marjon, K., Cameron, M., Quang, P., Clasquin, M., Mandley, E., Kunii, K., McVay, M., Choe, S., Kernytsky, A., Gross, S., Konteatis, Z., Murtie, J., Blake, M., Travins, J., Dorsch, M., Biller, S., and Marks, K. (2016) MTAP Deletions in Cancer Create Vulnerability to Targeting of the MAT2A/PRMT5/RIOK1 Axis. Cell Rep. 15, 574-587.

(9) Mavrakis, K. J., McDonald, E. R., Billy, E., Hoffman, G. R., deWeck, A., Ruddy, D. A., Venkatesan, K., Yu, J., McAllister, G., Stump, M., deBeaumont, R., Ho, S., Yue, Y., Liu, Y., Yan-Neale, Y., Yang, G., Lin, F., Yin, H., Gao, H., Kipp, D. R., Zhao, S., McNamara, J. T., Sprague, E. R., Zheng, B., Lin, Y., Cho, Y. S., Gu, J., Crawford, K., Ciccone, D., Vitari, A. C., Lai, A., Capka, V., Hurov, K., Porter, J. A., Tallarico, J., Mickanin, C., Lees, E., Pagliarini, R., Keen, N., Schmelzle, T., Hofmann, F., Stegmeier, F., Sellers, W. R., and Schlabach, M. R. (2016) Disordered methionine metabolism in MTAP/CDKN2A-deleted cancers leads to dependence on PRMT5. Science 351, 1208-1213.

(10) Singh, V., and Schramm, V. L. (2006) Transition-state structure of human 5'-methylthioadenosine phosphorylase. J. Am. Chem. Soc. 128, 14691-14696. 
(11) Evans, G. B., Furneaux, R. H., Lenz, D. H., Painter, G. F., Schramm, V. L., Singh, V., and Tyler, P. C. (2005) Second generation transition state analogue inhibitors of human $5^{\prime}$-methylthioadenosine phosphorylase. J. Med. Chem. 48, 4679-4689.

(12) Evans, G. B., Furneaux, R. H., Schramm, V. L., Singh, V., and Tyler, P. C. (2004) Targeting the polyamine pathway with transitionstate analogue inhibitors of $5^{\prime}$-methylthioadenosine phosphorylase. J. Med. Chem. 47, 3275-3281.

(13) Basu, I., Cordovano, G., Das, I., Belbin, T. J., Guha, C., and Schramm, V. L. (2007) A transition state analogue of 5'methylthioadenosine phosphorylase induces apoptosis in head and neck cancers. J. Biol. Chem. 282, 21477-21486.

(14) Basu, I., Locker, J., Cassera, M. B., Belbin, T. J., Merino, E. F., Dong, X., Schramm, V. L., Hemeon, I., Evans, G. B., and Guha, C. (2011) Growth and metastases of human lung cancer are inhibited in mouse xenografts by a transition state analogue of 5 -methylthioadenosine phosphorylase. J. Biol. Chem. 286, 4902-4911.

(15) Schramm, V. L. (2007) Enzymatic transition state theory and transition state analogue design. J. Biol. Chem. 282, 28297-28300.

(16) Eftink, M. R., Anusiem, A. C., and Biltonen, R. L. (1983) Enthalpy-entropy compensation and heat capacity changes for proteinligand interactions: general thermodynamic models and data for the binding of nucleotides to ribonuclease A. Biochemistry 22, 3884-3896.

(17) Guan, R., Ho, M. C., Brenowitz, M., Tyler, P. C., Evans, G. B., Almo, S. C., and Schramm, V. L. (2011) Entropy-driven binding of picomolar transition state analogue inhibitors to Human $5^{\prime}$-methylthioadenosine phosphorylase. Biochemistry 50, 10408-10417.

(18) Guan, R., Tyler, P. C., Evans, G. B., and Schramm, V. L. (2013) Thermodynamic analysis of transition-state features in picomolar inhibitors of human 5 -methylthioadenosine phosphorylase. Biochemistry 52, 8313-8322.

(19) Thomas, K., Haapalainen, A. M., Burgos, E. S., Evans, G. B., Tyler, P. C., Gulab, S., Guan, R., and Schramm, V. L. (2012) Femtomolar inhibitors bind to 5 '-methylthioadenosine nucleosidases with favorable enthalpy and entropy. Biochemistry 51, 7541-7550.

(20) Edwards, A. A., Mason, J. M., Clinch, K., Tyler, P. C., Evans, G. B., and Schramm, V. L. (2009) Altered enthalpy-entropy compensation in picomolar transition state analogues of human purine nucleoside phosphorylase. Biochemistry 48, 5226-5238.

(21) Fischer, S., Smith, J. C., and Verma, C. S. (2001) Dissecting the Vibrational Entropy Change on Protein/Ligand Binding: Burial of a Water Molecule in Bovine Pancreatic Trypsin Inhibitor. J. Phys. Chem. B 105, 8050-8055.

(22) Baker, B. M., and Murphy, K. P. (1998) Prediction of Binding Using Empirical Energetics from Structure Parameterization. Methods Enzymol. 295, 294-315.

(23) Hobbs, J. K., Jiao, W., Easter, A. D., Parker, E. J., Schipper, L. A., and Arcus, V. L. (2013) Change in heat capacity for enzyme catalysis determines temperature dependence of enzyme catalyzed rates. ACS Chem. Biol. 8, 2388-2393.

(24) Arcus, V. L., Prentice, E. J., Hobbs, J. K., Mulholland, A. J., Van der Kamp, M. W., Pudney, C. R., Parker, E. J., and Schipper, L. A. (2016) On the Temperature Dependence of Enzyme-Catalyzed Rates. Biochemistry 55, 1681-1688.

(25) Ho, M. C., Shi, W., Rinaldo-Matthis, A., Tyler, P. C., Evans, G. B., Clinch, K., Almo, S. C., and Schramm, V. L. (2010) Four generations of transition-state analogues for human purine nucleoside phosphorylase. Proc. Natl. Acad. Sci. U. S. A. 107, 4805-4812.

(26) Appleby, T. C., Erion, M. D., and Ealick, S. E. (1999) The structure of human $5^{\prime}$-deoxy-5'-methylthioadenosine phosphorylase at $1.7 \AA$ resolution provides insights into substrate binding and catalysis. Structure 7, 629-41.

(27) Gómez, J., Hilser, V. J., Xie, D., and Freire, E. (1995) The heat capacity of proteins. Proteins: Struct., Funct., Genet. 22, 404-12.

(28) Ertl, P., Rohde, B., and Selzer, P. (2000) Fast calculation of molecular polar surface area as a sum of fragment based contributions and its application to the prediction of drug transport properties. J. Med. Chem. 43, 3714-3717.
(29) Habermann, S. M., and Murphy, K. P. (1996) Energetics of hydrogen bonding in proteins: a model compound study. Protein Sci. 5, $1229-1239$.

(30) Greenfield, N. J. (2006) Using circular dichroism collected as a function of temperature to determine the thermodynamics of protein unfolding and binding interactions. Nat. Protoc. 1, 2527-2535.

(31) Hirschi, J. S., Arora, K., Brooks, C. L., and Schramm, V. L. (2010) Conformational Dynamics in Human Purine Nucleoside Phosphorylase with Reactants and Transition-State Analogues. J. Phys. Chem. B 114, $16263-16272$.

(32) Seewald, M. J., Pichumani, K., Stowell, C., Tibbals, B. V., Regan, L., and Stone, M. J. (2000) The role of backbone conformational heat capacity in protein stability: temperature dependent dynamics of the B1 domain of Streptococcal protein G. Protein Sci. 9, 1177-1193.

(33) Gomez, J., Hilser, V. J., Xie, D., and Freire, E. (1995) The heat capacity of proteins. Proteins: Struct., Funct., Genet. 22, 404-412.

(34) Singh, V., Shi, W., Evans, G. B., Tyler, P. C., Furneaux, R. H., Almo, S. C., and Schramm, V. L. (2004) Picomolar transition state analogue inhibitors of human $5^{\prime}$-methylthioadenosine phosphorylase and X-ray structure with MT-immucillin-A. Biochemistry 43, 9-18.

(35) Fiser, A., Do, R. K., and Sali, A. (2000) Modeling of loops in protein structures. Protein Sci. 9, 1753-1773.

(36) Bayly, C. I., Cieplak, P., Cornell, W. D., and Kollman, P. A. (1993) A Well-Behaved Electrostatic Potential Based Method Using Charge Restraints for Deriving Atomic Charges: The RESP Model. J. Phys. Chem. 97, 10269-10280.

(37) Wang, J., Wang, W., Kollman, P. A., and Case, D. A. (2006) Automatic atom type and bond type perception in molecular mechanical calculations. J. Mol. Graphics Modell. 25, 247-60.

(38) Wang, J., Wolf, R. M., Caldwell, J. W., Kollman, P. A., and Case, D. A. (2004) Development and testing of a general amber force field. J. Comput. Chem. 25, 1157-74.

(39) Hornak, V., Abel, R., Okur, A., Strockbine, B., Roitberg, A., and Simmerling, C. (2006) Comparison of multiple Amber force fields and development of improved protein backbone parameters. Proteins: Struct., Funct., Genet. 65, 712-725.

(40) Darden, T., York, D., and Pedersen, L. (1993) Particle mesh Ewald: An $\mathrm{N} \bullet \log (N)$ method for Ewald sums in large systems. J. Chem. Phys. 98, 10089-10092.

(41) Ryckaert, J. P., Ciccotti, G., and Berendsen, H. J. C. (1977) Numerical integration of the Cartesian equations of motion of a system with constaints: molecular dynamics of $n$-alkanes. J. Comput. Phys. 23, $327-343$.

(42) Firestone, R. S., Cameron, S. A., Tyler, P. C., Ducati, R. G., Spitz, A. Z., and Schramm, V. L. (2016) Continuous Fluorescence Assays for Reactions Involving Adenine. Anal. Chem. 88, 11860-11867.

(43) Otwinowski, S., and Minor, W. (1997) Processing of X-ray Diffraction Data Collected in Oscillation Mode. Methods Enzymol. 276, 307-326.

(44) Kabsch, W. (2010) Integration, scaling, space-group assignment and post-refinement. Acta Crystallogr., Sect. D: Biol. Crystallogr. 66, 133144.

(45) Vagin, A. A., and Teplyakov, A. (1997) MOLREP: an Automated Program for Molecular Replacement. J. Appl. Crystallogr. 30, 10221025.

(46) Murshudov, G. N., Skubák, P., Lebedev, A. A., Pannu, N. S., Steiner, R. A., Nicholls, R. A., Winn, M. D., Long, F., and Vagin, A. A. (2011) REFMAC5 for the refinement of macromolecular crystal structures. Acta Crystallogr., Sect. D: Biol. Crystallogr. 67, 355-367.

(47) Emsley, P., Lohkamp, B., Scott, W. G., and Cowtan, K. (2010) Features and development of Coot. Acta Crystallogr., Sect. D: Biol. Crystallogr. 66, 486-501.

(48) Lebedev, A. A., Young, P., Isupov, M. N., Moroz, O. V., Vagin, A. A., and Murshudov, G. N. (2012) JLigand: a graphical tool for theCCP4 template-restraint library. Acta Crystallogr., Sect. D: Biol. Crystallogr. 68, 431-440. 